\title{
Correction to: Laser Induced Dielectric Breakdown for Chemical Vapor Deposition by Hydrogen Reduction of Volatile Boron Halides $\mathrm{BCl}_{3}$ and $\mathrm{BF}_{3}$
}

\author{
I. B. Gornushkin ${ }^{1}$ - P. G. Sennikov² - R. A. Kornev ${ }^{2}$ - A. A. Ermakov² • V. E. Shkrunin ${ }^{2}$ \\ Published online: 29 August 2020 \\ (c) Springer Science+Business Media, LLC, part of Springer Nature 2020
}

\section{Correction to: Plasma Chemistry and Plasma Processing https://doi.org/10.1007/s11090-020-10096-w}

The original version of this article unfortunately contained a mistake in the abstract section and figure 7. The corrections are listed below.

The original article can be found online at https://doi.org/10.1007/s11090-020-10096-w.

I. B. Gornushkin

igor.gornushkin@bam.de

1 BAM Federal Institute for Materials Research and Testing, Richard-Willstätter-Strasse 11, 12489 Berlin, Germany

2 G.G. Devyatykh Institute of Chemistry of High-Purity Substances of RAS, 49 Tropinin Str., Nizhny Novgorod, Russia 603951 
(a) In the Abstract section: 4th line " $\mathrm{BCl}_{3}$ " is repeated twice. It should read as "A breakdown in mixtures of $\mathrm{BCl}_{3}$ and $\mathrm{BF}_{3}$ with hydrogen, argon, and methane are studied both theoretically and experimentally."

(b) Figure 7 is incorrect. The correct Fig. 7 is given below.
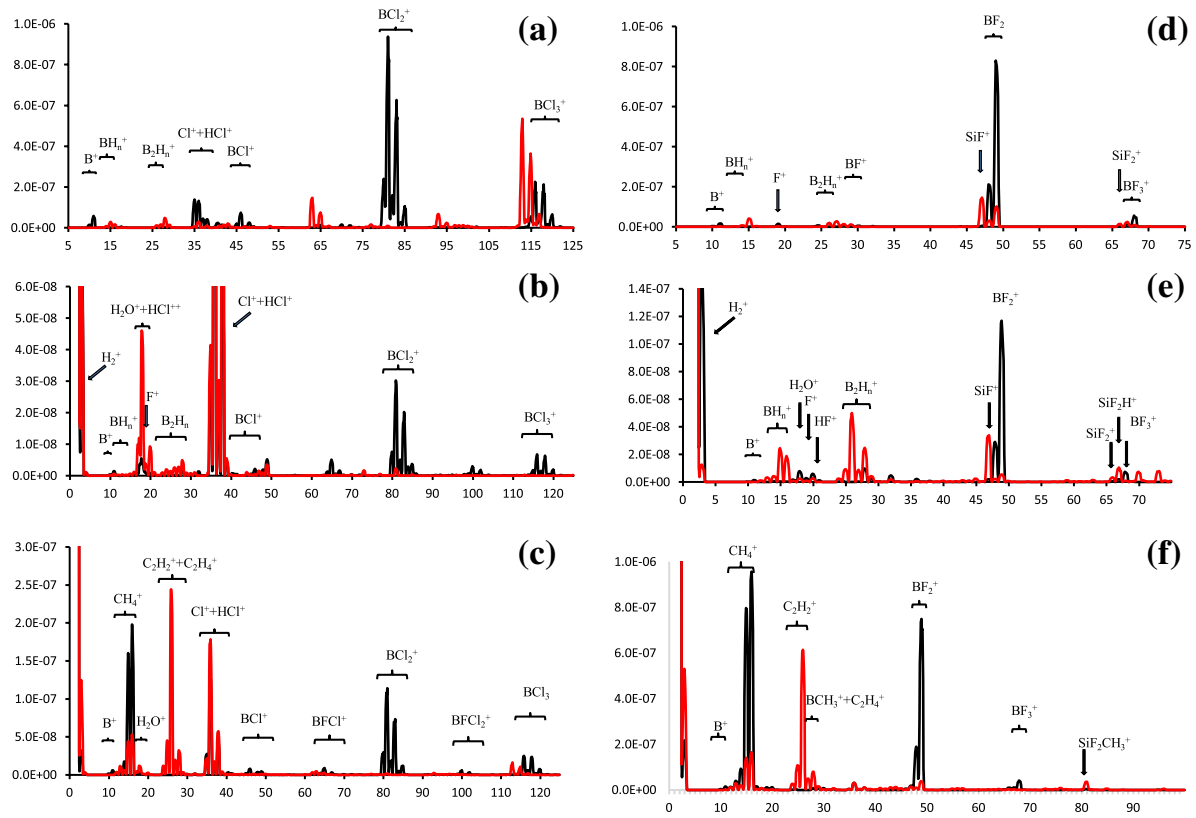

Fig. 7 MS spectra of a $\mathrm{BCl}_{3} ; \mathbf{b} \mathrm{BCl}_{3}+\mathrm{H}_{2} ; \mathbf{c} \mathrm{BCl}_{3}+\mathrm{H}_{2}+\mathrm{CH}_{4} ; \mathbf{d} \mathrm{BF}_{3}$; e $\mathrm{BF}_{3}+\mathrm{H}_{2}$; and $\mathbf{f} \mathrm{BF}_{3}+\mathrm{H}_{2}+\mathrm{CH}_{4}$. The black and red correspond to spectra taken before and after laser irradiation, correspondingly

Publisher's Note Springer Nature remains neutral with regard to jurisdictional claims in published maps and institutional affiliations. 